\title{
Temporal Changes and Alternating Host Tree Root and Shoot Growth Affect Soil Microbiomes ${ }^{\dagger}$
}

\author{
Jean de Dieu Habiyaremye 1,2,3,*, Sylvie Herrmann 1,4, François Buscot 1,2, and Kezia Goldmann ${ }^{1}$ \\ 1 Department of Soil Ecology, Helmholtz Centre for Environmental Research-UFZ, Theodor-Lieser-Str. 4, \\ 06120 Halle (Saale), Germany; Sylvie.herrmann@ufz.de (S.H.); francois.buscot@ufz.de (F.B); \\ kezia.goldmann@ufz.de (K.G.) \\ 2 Institute of Biology, Leipzig University, Johannisallee 21-23, 04103 Leipzig, Germany \\ 3 Department of Mathematics, Science and Physical Education, University of Rwanda, P.O. Box 55, \\ Rwamagana, Rwanda \\ 4 German Centre for Integrative Biodiversity Research (iDiv) Halle-Jena-Leipzig, Deutscher Platz 5e, \\ 04103 Leipzig, Germany \\ * Correspondence:jean-de-dieu.habiyaremye@ufz.de \\ + Presented at the 1st International Electronic Conference on Microbiology, 2-30 November 2020; Available \\ online: https://ecm2020.sciforum.net/.
}

Published: 13 January 2021

\begin{abstract}
Patterns of trees' endogenous rhythmic growth (ERG) and paralleled C allocation shift between root and shoot systems have been studied, but there is still a need to understand their impact in shaping soil microbiomes. Moreover, the impact of plants on soil microbial communities can be modulated or overweighed by time-induced plant and/or seasonal changes. Thus, we intended to analyze the structure of soil microbiomes as response to simultaneous alternated host tree root and shoot flushes and time-induced changes within one vegetation period at two sites in Central Germany. In this study, we utilized oak phytometers (Quercus robur L., clone DF159) as host trees, and made use of their ERG, whereby consecutive root and shoot flushes make a complete growth cycle. We studied two complete growth cycles during the same vegetation period, performed a non-destructive soil sampling and applied high-throughput amplicon sequencing of the bacterial 16S gene and the fungal ITS2 region. As $C$ allocation shifts between the tree root and shoot, released root exudates and consequently the nutrient availability alternate for soil microorganisms. We therefore anticipated different microbial communities in the host tree root zone along the growth cycles until autumnal leaf senescence. In our results, the bacterial community exhibited a directional change over time along the vegetation period. In contrast, the fungal community appeared sample specific. Our findings enlarge the current understanding of the temporal microbial assembly in the host tree root zone.
\end{abstract}

Keywords: tree endogenous rhythmic growth; microbial community structure; bacteria; fungi; timeinduced changes; tree root zone; Quercus robur L.

\section{Introduction}

Plant-root associated microorganisms feed primarily on plant rhizodeposits [1], of which the amount and dynamics are correlated with plant biomass [2]. Recently, a mesocosm experiment on annual dynamics of microbes associated with roots of grass and forb species found significant changes on the bacterial community over time, while the fungal community varied according to the host plant species [3]. However, this work did not consider the effects of plant development that occur over a vegetation period, and the sampling times were not determined according to phases of the plant development. 
Oak trees (Quercus robur L.) are characterized by an endogenous rhythmic growth (ERG) with an alternation of root flush (RF) and shoot flush (SF), which are constitutive of one rhythmic growth cycle [4]. This alternation can be followed by using anatomical shoot bud developmental stages from A to D [5]: bud resting for stage A indicates the end of a SF; bud swelling for stage B corresponds to ongoing RF; bud outbusting for stage $\mathrm{C}$ indicates the end of a RF; and leaf expansion from the bud known as stage D corresponds to a new SF. Over a vegetation period and depending on environmental parameters, oak trees can have one growth cycle (one RF and one SF), two growth cycles (RF1, SF1, RF2 and SF2) or even more cycles, concluded by the autumnal leaf senescence. The tree ERG is paralleled with high and low concentrations of photoassimilates in roots during the root and shoot flushes, respectively [6]. According to the "push" hypothesis, the more C "pushed" into roots, the more $\mathrm{C}$ ought to be exuded from roots [7]. This should induce changes in the tree root associated microbial communities.

In the current research, we considered oak time-induced changes and the ERG as a single time entity, and analyzed their impact on the tree root zone microbial communities over one vegetation period. Due to bacteria rapid response to environmental changes [3], we hypothesized (1) temporal changes in bacterial communities. We also predicted (2) changes of the fungal communities over time, due to their dependence on host plants and tight attachment to recently assimilated C [8].

\section{Materials and Methods}

The study was carried out at two grassland field sites in Central Germany: Bad Lauchstädt

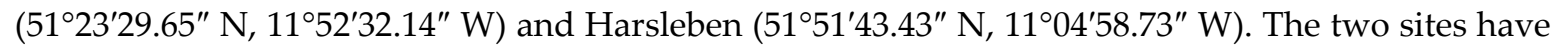
similar weather conditions due to their geographic proximity. Oak phytometers used for this study were outplanted at the sites in November 2014, and soil was sampled during the vegetation period 2018. Based on the tree bud development stages, we determined the times of RFs and SFs and respectively sampled at the ends of the tree $\mathrm{RF} 1, \mathrm{SF} 1, \mathrm{RF} 2, \mathrm{SF} 2$, and at the senescence to conclude the vegetation period.

Soil samples were taken in the tree root and root-free zones as described previously Habiyaremye, et al. [9], despite the upper $0-15 \mathrm{~cm}$ soil $30 \mathrm{~cm}$ from the tree trunk that were taken. Detailed descriptions of the molecular methods, from DNA extraction to Illumina-based sequencing were also published before [9]. Bioinformatics and processing of sequences data were conducted using the dadasnake pipeline (v0.5) [10], a DADA2 [11] implementation in snakemake [12].

Statistical analyses were performed using $\mathrm{R}$ v4.0.2 [13]. We performed a non-metric multidimensional scaling (NMDS) based on the Bray-Curtis dissimilarity matrices [14] to test divergences in the microbial communities over time. By using the function "adonis" of the vegan package v2.5-6 [15] we performed permutational analysis of variance (PERMANOVA) with 9999 permutations [16] to test the effect of sampling times for bacteria as well as sampling time and sampled position for the fungi. We further carried out Mantel correlation tests between a sampling time distance matrix (in days) and corresponding matrices of bacterial Bray-Curtis distances using 9999 permutations.

\section{Results and Discussion}

From both the NMDS plot and PERMANOVA results, bacterial community of the tree root and root-free zones changed between time points along a vegetation period $(p<0.001$ for both the tree root and root-free zone) (Figure 1A). Mantel correlation test revealed positive linear correlation between distance in time and dissimilarities among the bacterial communities (Bad Lauchstädt: $R=0.59, p<0.001$ in the tree root zone, and $R=0.67, p<0.001$ in the tree root-free zone; Harsleben: $R=0.65, p<0.001$ in the tree root zone, and $R=0.31, p=0.008$ in the tree root-free zone) (Figure 1B). 


\section{Bad Lauchstädt}

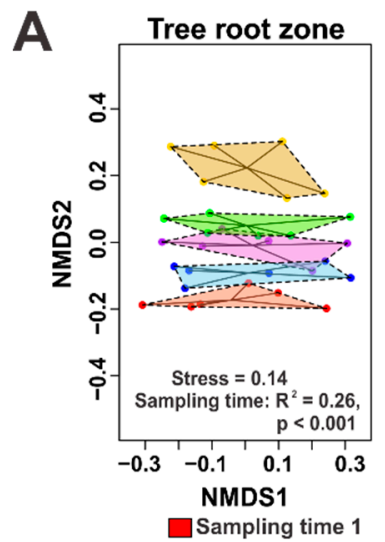

B

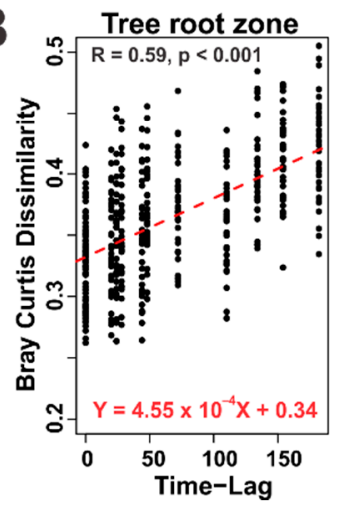

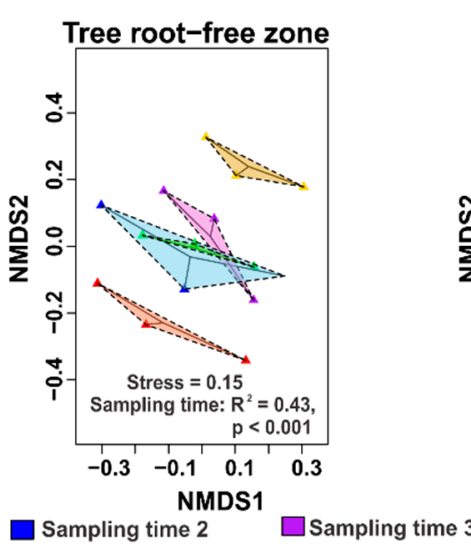
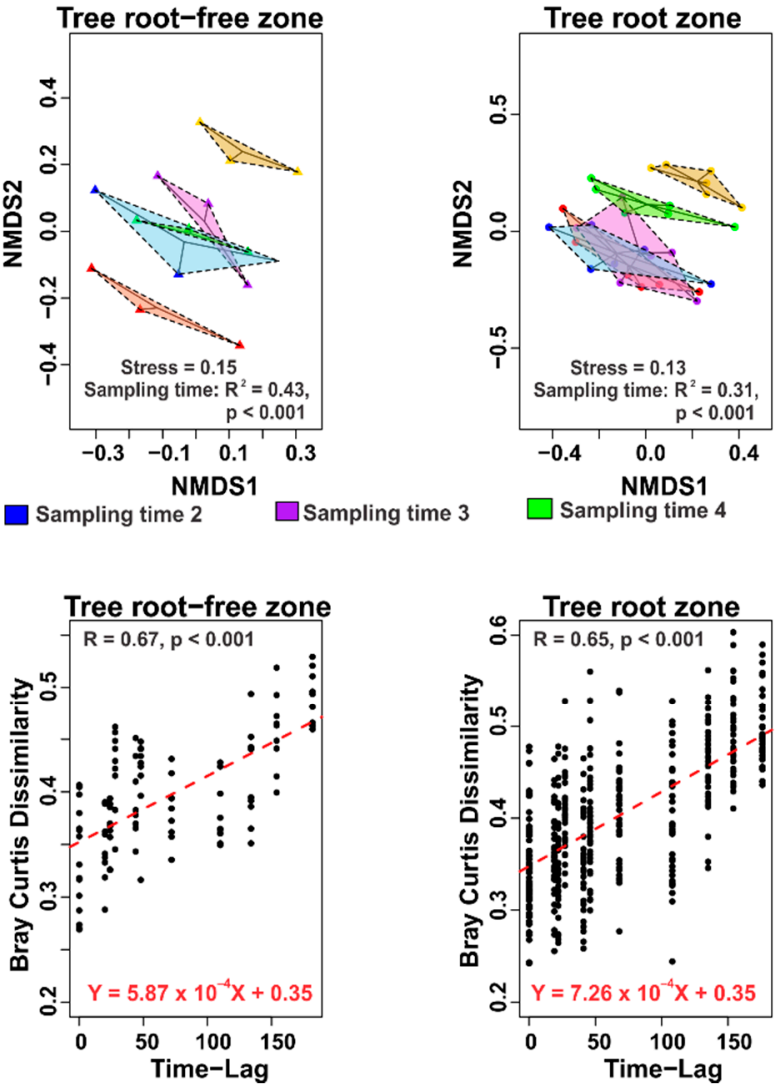

Harsleben
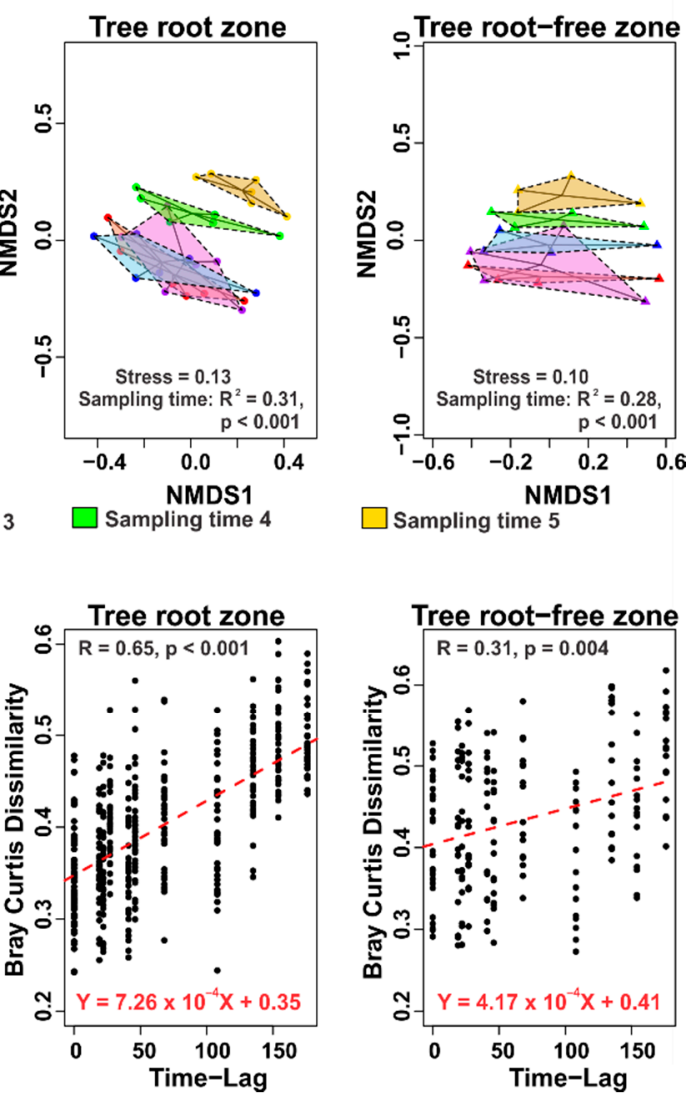

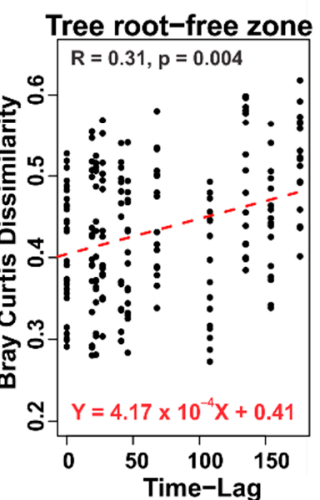

Figure 1. (A) Non-metric multidimensional scaling (NMDS) based on Bray-Curtis dissimilarity displaying bacterial community structure along with succession of sampling times. $R^{2}$ and $p$ values are PERMANOVA results showing the effect of sampling time points, which coincided with ends of the tree RF1, SF1, RF2, SF2, and the senescence. (B) Correlation between distance in time along vegetation period and Bray-Curtis dissimilarity among the bacterial communities. $R$ and $p$ values are Mantel correlation test results. Time-Lag here means number of days in-between sampling times.

For fungal community of the tree root zone, sampling time points showed either no impact (Harsleben, PERMANOVA: $p>0.05$ ) or less impact compared to sampled trees (Bad Lauchstädt, PERMANOVA: $R^{2}=0.13$ for sampling time and 0.50 for sampled trees, $p<0.001$ ). Within the tree rootfree zone, a fine-scale niche partitioning of the fungi was also noticed (Figure 2).

Our results confirmed the first hypothesis of temporal changes on the tree root zone bacterial community at both sites, Bad Lauchstädt and Harsleben. However, the second hypothesis of timeinduced changes on the fungal community over the vegetation period was only confirmed at Bad Lauchstädt and rejected at Harsleben. Short-term variability in bacterial communities was also previously reported $[17,18]$, while the majority of changes in soil fungal communities take place over longer time scales $[17,18]$. The rapid response of bacteria to environmental changes is a result of their relatively short generation times $[17,18]$, versus the relatively long generation times for the fungi $[3,17]$. Referring to solely effects of plant time-induced changes, the bacterial community variations may have been a result of increasing size and productivity of the host plants, and subsequent changes in quantity and quality of the rhizodeposits over the vegetation period. This could explain the changes noticed in both the tree root and root-free zones.

The fungal community underwent time-induced succession in one site only. The community showed rather always fine spatial scale changes which may be explained by concurrent plant-soil interactions at fine spatial scales [19] and the fungi high dependence on host plants [8]. 

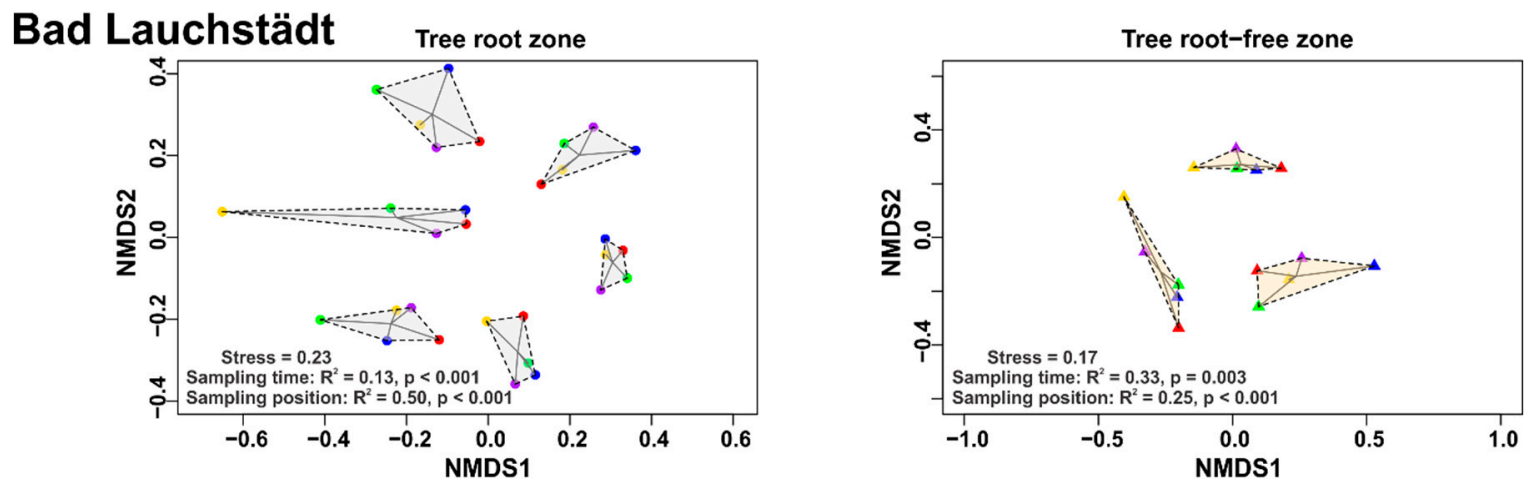

\section{Harsleben}

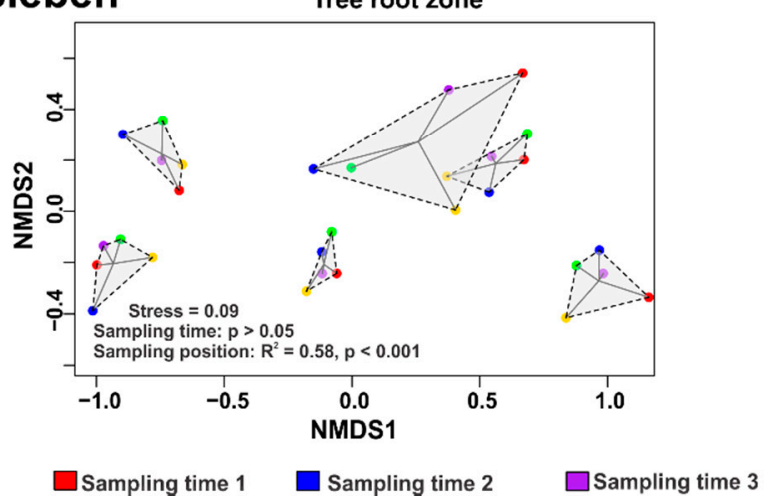

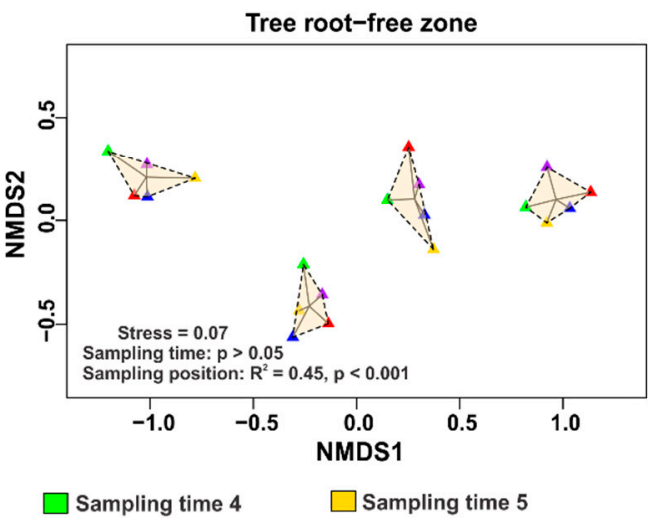

Figure 2. Non-metric multidimensional scaling (NMDS) based on Bray-Curtis dissimilarity displaying fine spatial scale partitioning of the fungal community. Sampling times coincided respectively with ends of the tree $\mathrm{RF} 1, \mathrm{SF} 1, \mathrm{RF} 2, \mathrm{SF} 2$, and the senescence.

\section{Conclusions}

Bacterial community structure in the root zone of the oak phytometers changed between time points along one vegetation period. On the contrary, the fungal community structure displayed fine spatial scale partitioning, closely linked to host plant individuals. The current research underlines the significance of repeated samplings over a vegetation period, but could not decouple respective impacts of time and ERG. Future studies should parallel rhythmically growing host trees with continuously growing trees, and track development of their root-associated microbial community over several consecutive vegetation periods to determine respective magnitude of time and host plant rhythmic growth.

Acknowledgments: We are thankful to the Soil Ecology Department of the Helmholtz Centre for Environmental Research (UFZ), especially the staff of the TrophinOak/PhytOakmeter project; to the German Academic Exchange Service (DAAD); and to the University of Rwanda.

\section{References}

1. Dennis, P.G.; Miller, A.J.; Hirsch, P.R. Are root exudates more important than other sources of rhizodeposits in structuring rhizosphere bacterial communities? FEMS Microbiol. Ecol. 2010, 72, 313-327.

2. Aulakh, M.; Wassmann, R.; Bueno, C.; Kreuzwieser, J.; Rennenberg, H. Characterization of root exudates at different growth stages of ten rice (Oryza sativa L.) cultivars. Plant Biol. 2001, 3, 139-148.

3. Hannula, S.E.; Kielak, A.M.; Steinauer, K.; Huberty, M.; Jongen, R.; De Long, J.R.; Heinen, R.; Bezemer, T.M. Time after Time: Temporal Variation in the Effects of Grass and Forb Species on Soil Bacterial and Fungal Communities. mBio 2019, 10, e02635-19, doi:10.1128/mBio.02635-19.

4. Herrmann, S.; Recht, S.; Boenn, M.; Feldhahn, L.; Angay, O.; Fleischmann, F.; Tarkka, M.T.; Grams, T.E.E.; Buscot, F. Endogenous rhythmic growth in oak trees is regulated by internal clocks rather than resource availability. J. Exp. Bot. 2015, 66, 7113-7127, doi:10.1093/jxb/erv408. 
5. Herrmann, S.; Grams, T.E.E.; Tarkka, M.T.; Angay, O.; Bacht, M.; Bönn, M.; Feldhahn, L.; Graf, M.; Kurth, F.; Maboreke, H., et al. Endogenous rhythmic growth, a trait suitable for the study of interplays between multitrophic interactions and tree development. Perspect. Plant Ecol. Evol. Syst. 2016, 19, 40-48, doi:10.1016/j.ppees.2016.02.003.

6. Angay, O.; Fleischmann, F.; Recht, S.; Herrmann, S.; Matyssek, R.; Oßwald, W.; Buscot, F.; Grams, T.E.E. Sweets for the foe-Effects of nonstructural carbohydrates on the susceptibility of Quercus robur against Phytophthora quercina. New Phytol. 2014, 203, 1282-1290, doi:10.1111/nph.12876.

7. Karst, J.; Gaster, J.; Wiley, E.; Landhäusser, S.M. Stress differentially causes roots of tree seedlings to exude carbon. Tree Physiol. 2016, 37, 154-164, doi:10.1093/treephys/tpw090.

8. Denef, K.; Roobroeck, D.; Manimel Wadu, M.C.W.; Lootens, P.; Boeckx, P. Microbial community composition and rhizodeposit-carbon assimilation in differently managed temperate grassland soils. Soil Biol. Biochem. 2009, 41, 144-153, doi:10.1016/j.soilbio.2008.10.008.

9. Habiyaremye, J.D.D.; Goldmann, K.; Reitz, T.; Herrmann, S.; Buscot, F. Tree root zone microbiome: exploring the magnitude of environmental conditions and host tree impact. Front. Microbiol. 2020, 11, 749.

10. Weißbecker, C.; Schnabel, B.; Heintz-Buschart, A. Dadasnake, a Snakemake implementation of DADA2 to process amplicon sequencing data for microbial ecology. GigaScience 2020, 9, giaa135, doi:10.1093/gigascience/giaa135.

11. Callahan, B.J.; McMurdie, P.J.; Rosen, M.J.; Han, A.W.; Johnson, A.J.A.; Holmes, S.P. DADA2: Highresolution sample inference from Illumina amplicon data. Nat. Methods 2016, 13, 581-583, doi:10.1038/nmeth.3869.

12. Köster, J.; Rahmann, S. Snakemake-A scalable bioinformatics workflow engine. Bioinformatics 2012, 28, 2520-2522, doi:10.1093/bioinformatics/bts480.

13. R Development Core Team. R: A Language and Environment for Statistical Computing. 2019. Available online: https://www.r-project.org (accessed on 17 August 2020).

14. Clarke, K.R. Non-parametric multivariate analyses of changes in community structure. Aust. J. Ecol. 1993, 18, 117-143.

15. Oksanen, J.; Blanchet, F.G.; Friendly, M.; Kindt, R.; Legendre, P.; McGlinn, D.; Minchin, P.; O’Hara, R.; Simpson, G.; Solymos, P.; et al. vegan: Community Ecology Package. R package Version 2.5-6; R Foundation for Statistical Computing: Vienna, Austria, 2019.

16. Anderson, M.J. A new method for non-parametric multivariate analysis of variance. Austral Ecol. 2001, 26, 32-46, doi:10.1111/j.1442-9993.2001.01070.pp.x.

17. Sun, S.; Li, S.; Avera, B.N.; Strahm, B.D.; Badgley, B.D. Soil Bacterial and Fungal Communities Show Distinct Recovery Patterns during Forest Ecosystem Restoration. Appl. Environ. Microbiol. 2017, 83, e00966-17, doi:10.1128/aem.00966-17.

18. Lauber, C.L.; Ramirez, K.S.; Aanderud, Z.; Lennon, J.; Fierer, N. Temporal variability in soil microbial communities across land-use types. ISME J. 2013, 7, 1641-1650, doi:10.1038/ismej.2013.50.

19. Burke, D.J.; López-Gutiérrez, J.C.; Smemo, K.A.; Chan, C.R. Vegetation and Soil Environment Influence the Spatial Distribution of Root-Associated Fungi in a Mature Beech-Maple Forest. Appl. Environ. Microbiol. 2009, 75, 7639-7648, doi:10.1128/aem.01648-09.

Publisher's Note: MDPI stays neutral with regard to jurisdictional claims in published maps and institutional affiliations.

(C) 2021 by the authors. Licensee MDPI, Basel, Switzerland. This article is an open access article distributed under the terms and conditions of the Creative Commons Attribution (CC BY) license (http://creativecommons.org/licenses/by/4.0/). 